ఠ

CASE REPORT

\title{
Adequate nutrition status important for bone mineral density improvement in a patient with anorexia nervosa
}

This article was published in the following Dove Press journal:

Therapeutics and Clinical Risk Management

\author{
Yukio Nakamura ${ }^{1,2}$ \\ Mikio Kamimura ${ }^{3}$ \\ Hidefumi Koiwai ${ }^{4}$ \\ Hiroyuki Kato' \\ 'Department of Orthopaedic \\ Surgery, Shinshu University School \\ of Medicine, Matsumoto, Japan; \\ ${ }^{2}$ Department of Orthopedic Surgery, \\ Showa-Inan General Hospital, \\ Komagane, Japan; ${ }^{3}$ Center of \\ Osteoporosis and Spinal Disorders, \\ Kamimura Orthopedic Clinic, \\ Matsumoto, Japan; ${ }^{4}$ Koiwai Orthopedic \\ Clinic, Komoro, Japan
}

\begin{abstract}
Low bone mineral density (BMD) is one of the most frequent complications of anorexia nervosa (AN). We report the clinical outcomes of a female patient with severe AN, whose chest had become deformed due to thoracic fracture. Lumbar BMD was $0.358 \mathrm{~g} / \mathrm{cm}^{2}$ ( -score $=-6.3)$, and total hip BMD was $0.411 \mathrm{~g} / \mathrm{cm}^{2}(\mathrm{~T}$-score $=-4.4)$. Active vitamin D increased these parameters by $81.0 \%$ and $57.4 \%$, respectively, but a drop in her nutrition status afterward resulted in a sharp decrease in BMD values. These findings suggest that adequate nutrient intake is essential for effective osteoporosis treatment in patients with AN.
\end{abstract}

Keywords: anorexia nervosa, bone mineral density, daily teriparatide, osteoporosis

\section{Introduction}

Anorexia nervosa (AN) is a severe eating disorder characterized by low body weight, intense fear of weight gain, and undue influence of weight and shape on self-evaluation. ${ }^{1}$ The overall age- and sex-adjusted incidence rate of AN is reportedly 4.1 per 100,000 person-years (95\% CI: 2.4-5.9), with a female-to-male ratio of age-adjusted rates of 1.2:1. ${ }^{2}$ AN tends to manifest during adolescence ${ }^{3}$ and has the highest mortality rate of any psychiatric disorder, with no gold standard treatment ${ }^{4}$ and high therapy dropout and relapse rates.

One of the first treatment approaches that were based on Bruch's observations was the "Maudsley model" of family therapy, in which the aim was to put patients in control of eating behavior. ${ }^{5}$ Approximately two-thirds of patients who receive this treatment as a form of early intervention show good recovery after 1 year, and this intervention is now recommended as a first-line treatment for adolescents with AN. ${ }^{6}$ However, it is important to note that this approach was not found to be effective if the illness had persisted for more than 3 years, or if the onset of the disorder occurred after the age of 18 years.

Numerous reports on AN and osteoporosis (OP) have surfaced over the past 3-4 decades. El Ghoch et $\mathrm{al}^{7}$ recently reviewed that diminished bone mineral density (BMD) was one of the most frequent medical complications in AN; nearly $85 \%$ of females with AN have very low BMD, and consequently, a sevenfold increase in the risk of spontaneous fracture compared with healthy controls. McAnarney et $\mathrm{al}^{8}$ described multiple rib fractures in a patient with AN as a result of forced vomiting in an individual with fragile bones. Khosla et $\mathrm{al}^{2}$ reported a preponderance of cancellous bone fractures in AN individuals (vertebral: 81\%; rib: 37\%; wrist: 13\%), with 13\% experiencing hip fracture.
Correspondence: Yukio Nakamura Department of Orthopaedic Surgery, Shinshu University School of Medicine, Asahi 3-I-I, Matsumoto 390-862I, Japan

$\mathrm{Tel}+81263372659$

Fax +8I 263358844

Email yxnI4@aol.jp 
The current first-line drugs for OP are bisphosphonates (BPs). Third-generation nitrogen-containing BPs inhibit farnesyl pyrophosphate synthetase in the mevalonate pathway in osteoclasts. ${ }^{9}$ Various other drugs have been described for patients with OP, such as the active vitamin D analog and $1 \alpha(\mathrm{OH})$ vitamin $\mathrm{D}_{3}$ (alfacalcidol; ALF), frequently used in Japan.

Concerning the treatment of adolescents with $\mathrm{AN}$ and OP, most methods tested (eg, hormone replacement, oral contraceptive pills, and BPs) have yielded only modest or negligible BMD improvements, ${ }^{10}$ with no data on the effectiveness of other strategies, such as physical activity intervention and/or the available nutritional supplementation (calcium, vitamin $\mathrm{D}$, etc). ${ }^{8}$ The only promising pharmacological treatment to date has been physiological estrogen replacement by means of transdermal estradiol associated with cyclic progesterone, which, despite comparable weight gains, was associated with a significantly greater increase in spine and hip BMD than a placebo in non-severely underweight adolescents with AN. ${ }^{11}$ However, these findings require replication in patients with more severe malnutrition.

\section{Case report}

The patient was a 32-year-old female with a weight of $43 \mathrm{~kg}$ and a height of $157 \mathrm{~cm}$. Since she has refused to know her body weight at all times, we have not measured it after she visited us for the first time. She had a medical history of pubic fracture and had been an outpatient at Shinshu University School of Medicine for 10 years following hospitalization for severe weight loss.

Her chief complaints were bilateral thoracic pain that had suddenly manifested 1 month prior and a common cold persisting for 2 months. The pain was obvious when taking a deep breath, coughing, or rolling over. The rib cage had become deformed to resemble the circumference of a barrel.

On presentation, her lumbar 1-4 BMD (L-BMD) was $0.358 \mathrm{~g} / \mathrm{cm}^{2}$ (T-score $=-6.3$ ), and bilateral total hip BMD (H-BMD) was $0.411 \mathrm{~g} / \mathrm{cm}^{2}(\mathrm{~T}$-score $=-4.4)$. Spinal plain radiographs showed no apparent fractures. Serum albumin was $4.3 \mathrm{~g} / \mathrm{dL}$, and $1,25(\mathrm{OH})_{2} \mathrm{D}_{3}$ was $35.1 \mathrm{pg} / \mathrm{dL}$; both were within normal range. Serum bone alkaline phosphatase (BAP) was 212.0 U/L, and urinary N-terminal telopeptide of type I collagen was $226.0 \mathrm{nmol} \mathrm{BCE} / \mathrm{mmol} \mathrm{Cr}$, which indicated extremely accelerated bone metabolism (Tables 1 and 2). She was diagnosed as having OP based on BMD measured by dual-energy X-ray absorption, for which ALF treatment was soon commenced. Thoracic pain subsided thereafter.
Table I Changes in serum TP, Alb, and ALP

\begin{tabular}{lllllllll}
\hline OP & $\mathbf{0} \mathbf{M}$ & $\mathbf{2} \mathbf{M}$ & $\mathbf{I} \mathbf{Y}$ & $\mathbf{2} \mathbf{Y}$ & $\mathbf{2 . 5} \mathbf{Y}$ & $\mathbf{3} \mathbf{Y}$ & Unit & Reference \\
\hline $\mathrm{TP}$ & 6.6 & 6.5 & 6.5 & 6.8 & 5.9 & 4.9 & $\mathrm{~g} / \mathrm{dL}$ & $6.6-8.3$ \\
Alb & 4.3 & 4.3 & 4.3 & 4.5 & 3.9 & 3.4 & $\mathrm{~g} / \mathrm{dL}$ & $3.7-4.9$ \\
ALP & $\mathrm{I}, 187$ & $\mathrm{I}, 092$ & 307 & 215 & $\mathrm{I} 77$ & $\mathrm{I} 24$ & $\mathrm{U} / \mathrm{L}$ & $105-368$ \\
\hline
\end{tabular}

Abbreviations: Alb, albumin; ALP, alkaline phosphatase; M, month(s); OP, observational period; TP, total protein; $Y$, year(s).

The values of bone turnover markers were gradually decreased after the therapy. At 3 years of treatment, alkaline phosphatase was $124 \mathrm{U} / \mathrm{L}(89.6 \%$ decrease from peak value), and BAP was $11.6 \mathrm{U} / \mathrm{L}$ (94.9\% decrease from peak value). $25(\mathrm{OH}) \mathrm{D}$ and deoxypyridinoline values were slightly elevated, and tartrate-resistant acid phosphatase-5b was within normal range, showing no obvious acceleration of bone metabolism.

In 8 months of treatment, the percentage changes of L-BMD or H-BMD were increased to $70.7 \%$ or $41.4 \%$, respectively. With respect to the peak values, L-BMD was $0.647 \mathrm{~g} / \mathrm{cm}^{2}$ (T-score $=-2.4 ; 81.0 \%$ increase; Figure 1$)$, and H-BMD was $0.648 \mathrm{~g} / \mathrm{cm}^{2}$ (T-score $=-3.5 ; 57.4 \%$ increase; Figure 2$)$.

She started to complain of deterioration of unbalanced diet and weight loss after the 2.5 -year treatment. Her nutritional status soon degenerated, and serum albumin decreased to $3.4 \mathrm{~g} / \mathrm{dL}$. At 4 years of treatment, L-BMD had fallen to $0.484 \mathrm{~g} / \mathrm{cm}^{2}(\mathrm{~T}$-score $=-4.7 ; 25.2 \%$ decrease from peak value), and $\mathrm{H}-\mathrm{BMD}$ was $0.605 \mathrm{~g} / \mathrm{cm}^{2}(\mathrm{~T}$-score $=-2.7 ; 6.6 \%$ decrease from peak value).

This patient gave written informed consent to publication of the patient's personal medical information prior to her inclusion in this report.

\section{Discussion}

There have been numerous reports of accelerated bone resorption and inhibited bone formation in AN. ${ }^{12,13}$ In the current case, both bone resorption and bone formation were initially accelerated. We previously reported that bone turnover markers were significantly increased with accompanying back pain in elderly women, presumably due to insufficiency fracture, ${ }^{12}$ and that various bone fragility fractures might increase bone turnover markers. ${ }^{13}$ Our patient had suffered multiple fractures prior to her visit to our facility, and her thoracic circumference resembled that of a barrel. Thus, her fractures might have caused a remarkable increase in bone turnover markers. Despite the nonuse of bone anti-resorptive drugs, her BAP decreased from 228.0 to $11.6 \mathrm{U} / \mathrm{L}$ (94.9\%) over 3 years, suggesting that bone metabolism improved from fracture healing. In patients with AN showing exceptional 
Table 2 Changes in serum BAP, urinary NTX, I, serum $25(\mathrm{OH})_{2} \mathrm{D}_{3}, 25(\mathrm{OH}) \mathrm{D}_{3}$, DPD, ucOC, and TRACP-5b

\begin{tabular}{lllllllll}
\hline & $\mathbf{0} \mathbf{M}$ & $\mathbf{2} \mathbf{M}$ & $\mathbf{I} \mathbf{Y}$ & $\mathbf{2} \mathbf{Y}$ & $\mathbf{2 . 5} \mathbf{Y}$ & $\mathbf{3} \mathbf{Y}$ & Unit & Reference \\
\hline BAP & 212.0 & 228.0 & 55.0 & 29.1 & 22.6 & $1 \mathrm{l} .6$ & $\mathrm{U} / \mathrm{L}$ & $9.6-35.4$ \\
Urinary NTX & 226.0 & 276.2 & 152.9 & 92.5 & 118.2 & - & $\mathrm{nmol}$ BCE $/ \mathrm{mmol} \mathrm{Cr}$ & $95-54.3$ \\
I,25(OH) $\mathrm{D}_{3}$ & - & 35.1 & 43.3 & - & - & - & $\mathrm{Pg} / \mathrm{mL}$ & $20-60$ \\
$25(\mathrm{OH}) \mathrm{D}_{3}$ & - & - & - & - & - & 5.0 & $\mathrm{ng} / \mathrm{mL}$ & $7-4 \mid$ \\
DPD & - & - & - & - & - & 11.7 & $\mathrm{nmol} \mathrm{BCE} / \mathrm{mmol} \mathrm{Cr}$ & $2.8-7.6$ \\
ucOC & - & - & - & - & - & 0.38 & $\mathrm{ng} / \mathrm{mL}$ & $<4.5$ \\
TRACP-5b & - & - & - & - & - & 149 & $\mathrm{mU} / \mathrm{dL}$ & $120-420$ \\
\hline
\end{tabular}

Abbreviations: BAP, bone alkaline phosphatase; DPD, deoxypyridinoline; M, month(s); NTX, N-terminal telopeptide of type-I collagen; TRACP, tartrate-resistant acid phosphatase; ucOC, undercarboxylated osteocalcin; $Y$, year(s).

bone metabolism, especially the enhancement of bone formation marker, very severe AN complicated with fracture and pain is highly probable.

Evidence from a large number of studies has suggested that weight recovery in adolescents with AN may not be sufficient to fully reverse the detrimental effects of prolonged undernutrition on skeletal development. The benefits of exercise and calcium/vitamin D supplementation on BMD in patients with AN are also equivocal. ${ }^{14}$ Russell et a ${ }^{10}$ have reported that BPs can be an agent to treat AN except for premenopausal women and that the increase in L-BMD or $\mathrm{H}$-BMD was $3 \%-4 \%$ or $2 \%$, respectively. Isobe et a $1{ }^{15}$ have recently reported that denosumab was effective for three patients with AN. In their report, the increases in L-BMD or H-BMD in those three cases were $15.7 \%, 18.6 \%$, or none, and $35.2 \%, 11.6 \%$, or $10.7 \%$, respectively. Compared with those data, this study showed that the increase in L-BMD or H-BMD was $81 \%$ or $57.4 \%$ at the best during the study period, which showed a much better improvement than that in their study. ${ }^{17}$

In this article, the increase in L-BMD was $70.7 \%$ and that in H-BMD was $41.4 \%$ at only 8 months of the treatment,



Figure I L-BMD $\left(0.358 \mathrm{~g} / \mathrm{cm}^{2} ;\right.$ T-score $\left.=-6.3\right)$ prior to treatment. Note: At 3 years of therapy, it was $0.647 \mathrm{~g} / \mathrm{cm}^{2}$ (T-score $=-2.4 ; 57.4 \%$ increase). Abbreviations: BMD, bone mineral density; L-BMD, lumbar I-4 BMD. which was too excellent considering her therapy being vitamin $\mathrm{D}$ alone. In our report on pregnancy and lactationassociated OP, we described two cases occurring in the early postpartum period that led to multiple spinal compression fractures. ${ }^{16}$ BMD gains were impressive in the early phases of treatment by combined vitamins $\mathrm{D}$ and $\mathrm{K}$ as follows: $19.7 \%$ at 1 year, $23.3 \%$ at 2 years, and $36.1 \%$ at 4 years in one case and $13.3 \%$ at 1 year, $17.3 \%$ at 2 years, and $26.3 \%$ at 3 years in the other (unpublished data). Thus, combination vitamin D and $\mathrm{K}$ therapy enabled a marked gradual increase in BMD in pregnancy and lactation-associated OP. In these cases, T-score of L-BMD was $-3.6 \mathrm{SD}$ and $-3.7 \mathrm{SD}$, respectively, revealing that the BMD values were decreased markedly. In this study, the T-score of L-BMD or H-BMD was -6.3 SD or $-4.4 \mathrm{SD}$, those of which were greatly decreased compared with those in their cases. ${ }^{16}$ Based on those findings and the results of the current case of AN, decreased BMD by repetitive fractures could be naturally recovered to some extent? We speculate that vitamin D and/or K may be instrumental in this process.

When our patient's AN status deteriorated after year 3, serum albumin became decreased from 4.3 to $3.4 \mathrm{~g} / \mathrm{dL}$ and



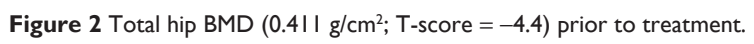
Note: At 3 years of therapy, it was $0.648 \mathrm{~g} / \mathrm{cm}^{2}$ (T-score $=-3.5 ; 81 \%$ increase). Abbreviation: BMD, bone mineral density. 
$25(\mathrm{OH}) \mathrm{D}_{3}$ remained at $5.0 \mathrm{ng} / \mathrm{mL}$ regardless of active vitamin $\mathrm{D}$ administration. Serum $25(\mathrm{OH}) \mathrm{D}_{3}$ is the major and main storage form of vitamin $\mathrm{D}$ whose sufficiency level is estimated as $20-30 \mathrm{ng} / \mathrm{mL}$. Therefore, $5.0 \mathrm{ng} / \mathrm{dL}$ represented a serious vitamin D deficiency, and BMD rapidly decreased irrespective of vitamin D continuation. Jáuregui-Lobera et $\mathrm{al}^{17}$ reported that the most effective strategy to recover BMD in AN seems to be weight gain and menstrual recovery. Indeed, the improvement in nutrition may supersede all other treatment modalities for OP associated with AN.

Overall, it appeared that worsened AN causing inadequate nutrition and a rapid decline in BMD that was refractory to active vitamin D therapy may have increased our patient's risk of fracture. Accordingly, anti-resorption drugs may be advocated for OP complicated with AN, especially when nutrition status may become compromised.

\section{Disclosure}

The authors report no conflicts of interest in this work.

\section{References}

1. APA. Diagnostic and Statistical Manual of Mental Disorders. 5th ed. Arlington, TX: American Psychiatric Publishing; 2013.

2. Khosla S, Lufkin EG, Hodgson SF, Fitzpatrick LA, Melton LJ 3rd. Epidemiology and clinical features of osteoporosis in young individuals. Bone. 1994;15(5):551-555.

3. Micali N, Hagberg KW, Petersen I, Treasure JL. The incidence of eating disorders in the UK in 2000-2009: findings from the General Practice Research Database. BMJ Open. 2013;3:e02646.

4. National Institute for Health and Clinical Excellence. Eating Disorders: Core Interventions in the Management of Anorexia Nervosa, Bulimia Nervosa and Related Eating Disorders. Leicester: British Psychological Society; 2004.

5. Russell GF, Szmukler GI, Dare C, Eisler I. An evaluation of family therapy in anorexia nervosa and bulimia nervosa. Arch Gen Psychiatry. 1987; 44:1047-1056.
6. Lock J. An update on evidence-based psychosocial treatments for eating disorders in children and adolescents. J Clin Child Adolesc Psychol. 2015;44:707-721.

7. El Ghoch M, Gatti D, Calugi S, Viapiana O, Bazzani PV, Dalle Grave R. The association between weight gain/restoration and bone mineral density in adolescents with anorexia nervosa: a systematic review. Nutrients. 2016;8(12):E769.

8. McAnarney ER, Greydanus DE, Campanella VA, Hoekelman RA. Rib fractures and anorexia nervosa. J Adolesc Health Care. 1983; 4(1):40-43.

9. Ste-Marie LG, Brown JP, Beary JF, et al. Comparison of the effects of once-monthly versus once-daily risedronate in postmenopausal osteoporosis: a phase II, 6-month, multicenter, randomized, double-blind, active-controlled, dose-ranging study. Clin Ther. 2009;31:272e85.

10. Sullivan PF. Mortality in anorexia nervosa. Am J Psychiatry. 1995;152: 1073-1074.

11. Misra M, Golden NH, Katzman DK. State of the art systematic review of bone disease in anorexia Nervosa. Int J Eat Disord. 2016;49: 276-292.

12. Kamimura $\mathrm{M}$, Uchiyama $\mathrm{S}$, Takahara $\mathrm{K}$, Hashidate $\mathrm{H}$, Kawaguchi $\mathrm{A}$, Nakagawa H. Urinary excretion of type I collagen cross-linked $\mathrm{N}$-telopeptide and serum bone-specific ALP in patients with osteoporosis. Age-related changes in elderly women with back pain. $J$ Bone Miner Metab. 2005;23:495-500.

13. Takahara K, Kamimura M, Nakagawa H, Uchiyama S. Changes in biochemical markers of bone in patients with insufficiency fractures. J Bone Miner Metab. 2004;22:618-625.

14. Bonjour JP, Kohrt W, Levasseur R, Warren M, Whiting S, Kraenzlin M. Biochemical markers for assessment of calcium economy and bone metabolism: application in clinical trials from pharmaceutical agents to nutritional products. Nutr Res Rev. 2014;27:252-267.

15. Isobe F, Nakamura Y, Suzuki T, Kato H. Effects of denosumab on osteoporosis in three cases with anorexia nervosa and a review of the literature. Mod Rheumatol Case Rep. 2018;2:104-106.

16. Nakamura Y, Kamimura M, Ikegami S, et al. A case series of pregnancyand lactation-associated osteoporosis and a review of the literature. Ther Clin Risk Manag. 2015;11:1361-1365.

17. Jáuregui-Lobera I, Bolaños-Ríos P, Sabaté J. Bone mineral density in anorexia nervosa: only weight and menses recovery? Endocrinol Nutr. 2016;63:458-465.
Therapeutics and Clinical Risk Management

\section{Publish your work in this journal}

Therapeutics and Clinical Risk Management is an international, peerreviewed journal of clinical therapeutics and risk management, focusing on concise rapid reporting of clinical studies in all therapeutic areas, outcomes, safety, and programs for the effective, safe, and sustained use of medicines. This journal is indexed on PubMed Central, CAS,

\section{Dovepress}

EMBase, Scopus and the Elsevier Bibliographic databases. The manuscript management system is completely online and includes a very quick and fair peer-review system, which is all easy to use. Visit $\mathrm{http}: / /$ www.dovepress.com/testimonials.php to read real quotes from published authors. 